\title{
Lightning protection of a temporary structure in open area
}

\author{
Satheesh Jacob, \\ Ramboll, London UK \\ Satheesh.jacob@ramboll.co.uk \\ Dr WH Siew \\ University of Strathclyde \\ Glasgow, UK \\ wh.siew@strath.ac.uk
}

\author{
Nadeem Basharat \\ Ramboll, Glasgow UK \\ Nadeem.basharat@ramboll.co.uk \\ Seungjae Choi \\ University of Strathclyde \\ Glasgow UK
}

\begin{abstract}
The current lightning protection systems are well proven and widely deployed for general situation. However, the methodology may be inadequate when applied to various situations especially in open area because the current BS EN and international standards do not cover guidance or procedures for lightning protection in open areas. The fundamental principle of lightning safety is 'No place outside is safe when thunderstorms are in the area!' The purpose of this research is to provide an outline of the lightning protection system strategy for the protection of life, livestock, sensitive equipment and property in open areas. The research proposes alternative methodology that can be used in open area for safety rather than the No-Notice personal backcountry lightning risk reduction process. Based on the results a suitable protection mechanism shall be developed to concept stage.
\end{abstract}

Keywords- lightning; temporary; structure; protection; mitigation

\section{INTRODUCTION}

Although the lightning protection method is well proven and widely deployed for general built environments, the method may be inadequate when applied to various situations. This may be especially true in open areas and temporary structures as the current British and international standards only offer lightning protection for permanent general fixed structures. Worldwide, around fifty percent of the population live in urban area, however, about one billion people live in slums and over 1.6 billion people live in inadequate housing or no shelter around the world [1]. Furthermore, UN-Habitat estimated the world slum may increase by an additional three billion people and about two fifth of the world's population will need permanent structure. Surprisingly, about a quarter of world population still lives in substandard conditions and they may not have any form of lightning protection at all.

\section{OPEN AREA}

Lightning striking an open area is natural phenomenon and frequently occurs. There are no specific paths that could intercept the lightning flashes. Therefore, it is assumed that lightning flashes may be equally distributed in the area and there are no specific objects need to be protected. According to previous report [2], from 2008 to 2012 there was an average of
9,000 wildfires started by lightning in the USA only and these fires burned an average of 402 acres. In addition, 38 firefighters were killed as a result of lightning-caused wild land fires from 2003 to 2012 and 116 people died as a result of lightning strikes from 2008 to 2012. The most common location for these deaths was outside or in an open area. There are no defined risk in accordance with current standard, however, lightning striking an open area can cause wild fire in many areas and destroy surrounding environment. It may trigger physical damage on the area and may loss of cultural heritage due to risk of fire by direct striking.

This paper researches a specific open area scenario with regards to temporary structures. The findings of this research shall be beneficial to address a number of real life open area situations in the area of defence, sports, adventure, agriculture and entertainment.

\section{METHODOLOGY}

The current standard [3] defines that the lightning current is the source of damage and there are four damage cases which are:

\section{S1: flashes to the structure;}

S2: flashes near the structure;

S3: flashes to the lines connected to the structure;

S4: flashes near the lines connected to the structure.

By analysing open area in backcountry situations similarly to the general structure in urban area, only flashes to an object (S1) and flashes near an object (S2) are need to be considered. Flashes to an object may cause immediate mechanical damage to sensitive equipment, fire and/or explosion due to the lightning current, or injury to living beings by electric shock due to direct strike, step or contact voltages. Flashes near an object can result in failure or malfunction of equipment due to overvoltage, or injury to living beings by electric shock due to side flash, step voltage or upward leader. As a result of lightning striking, it can cause three basic types of damage as defined in the standard [3] which are: 


\section{D1: injury to living beings by electric shock;}

D2: physical damage (fire, explosion, mechanical destruction) due to the lightning current effects, including sparking.

D3: failure of internal systems

Each type of damage alone or in combination with others may result in different loss. As like the standard the following types of loss should be considered in open area:

\section{L1: loss of human life (including permanent injury)}

L3: loss of cultural heritage (including endangered animal)

L4: loss of economic value (structure, its content and loss of activity).

Risks due to the type of loss resulting from type of damage are:

R1: risk of loss of human life;

R3: risk of loss of cultural heritage;

R4: risk of loss of economic values.

Both L2 and R2 are not considered because this study assumed that there is no service to public in open area. Figure 1 illustrates the corresponding risks of each type of loss.

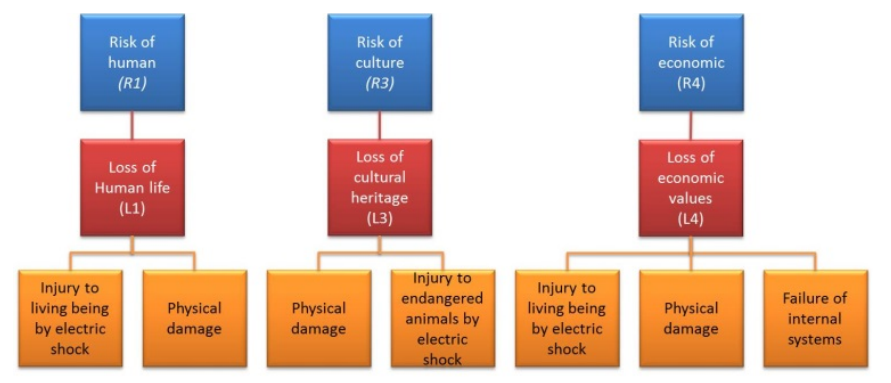

Figure 1 Corresponding risks

\section{TEMPORARY STRUCTURE}

Temporary structures area widely used in open area such as marquee, tent, transportable metal shelter and facilities for outdoor activities. For example, marquees are used for festivals or events, tents are used for wedding event, circus or military temporary accommodation for field drill, transportable metal shelters are used for not only temporary accommodation but also office facility when military dispatch of troops to overseas, construct dam, build wind farm or road building on rural sites. Concert stage and tower are kind of temporary facility for outdoor. These temporary structures have large concentration of people in them in the event and might have lines connected to the structure. In open area these temporary structures may only elevated object and relatively bigger size. Therefore, it has more possibility to be struck. 10 people were killed and 110 were injured by lightning in the US from 1991 to 1994 [4]. Flashes on the structure (S1) and near an object (S2) have risk of loss of human life (R1), risk or loss of economic value (R4). These risks will cause injury to living being by electric shock, physical damage, fire and failure of internal system.

\section{ANALYISIS}

When an upward leader from an object connects to one of the branch of the downward stepped leader, lightning may strike the object. If an object which height less than $100 \mathrm{~m}$, all lightning flashes is expected to be downward initiated by downward stepped leader from the cloud to the ground. Therefore, considering how often an object can be struck by lightning depend on horizontal distance from the edge of the object over a point where the attachment process can occur [1]. The number of dangerous event due to lightning is expressed as

$N_{D}=A_{D} \times N_{g} \times C_{D} \times 10^{-6}$

where, $\boldsymbol{A}_{\boldsymbol{D}}$ is square metres and called the "collection area" which is the equivalent cross sectional area for an isolated rectangular structure [5], $\boldsymbol{N}_{\boldsymbol{g}}$ is the number of flashes to ground per square kilometre per year $\left(\boldsymbol{N}_{\boldsymbol{g}} / \mathbf{k m}^{2} /\right.$ year $)$ and $C_{D}$ depends on the surrounding environment of the structure and its value for isolated structure is 1 . Collection area which relevant to flashes nearby a structure is shown in figure 2 and formulated as

$$
A_{D}=L \times W+2 \times(3 \times H) \times(L+W)+\pi \times(3 \times H)^{2}
$$
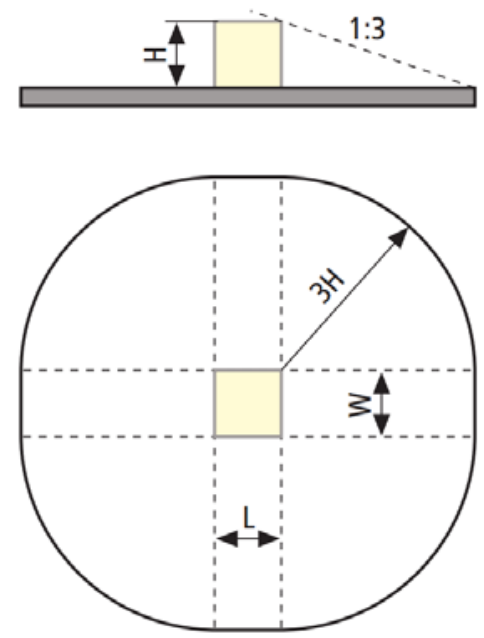

Figure 2 Collection area $\boldsymbol{A}_{\boldsymbol{D}}$ for direct lightning strikes into a standalone structure [5]

For the purpose of calculation, if the movable temporary circus tent is $10 \mathrm{~m}$ length, $10 \mathrm{~m}$ width and $7 \mathrm{~m}$ height, assuming lightning density of the region is about $20 / \mathrm{km}^{2}$ / year and the tent is rectangular shape.

$A_{D}=2325.442 \mathrm{~m}^{2}=0.002325 \mathrm{~km}^{2}$.

Thus

$N_{g} \times 0.002325 \approx 0.0466$ strikes to the structure per year. Around one twentieth of a strike per year is equivalent to one strike every 21.5 years on average. By considering open area scenarios for typical family size camping tent $(\mathrm{L}: 6.1 \mathrm{~m}, \mathrm{~W}$ : $3.8 \mathrm{~m}, \mathrm{H}: 2.15 \mathrm{~m})$, transportable metal shelters $(\mathrm{L}: 6.1 \mathrm{~m}, \mathrm{~W}$ : 2.44m, H: $2.59 \mathrm{~m}$ ), the FV4034 "Challenger 2" which is the UK main battle tank (L: $11.55 \mathrm{~m}, \mathrm{~W}: 3.5 \mathrm{~m}, \mathrm{H}: 2.5 \mathrm{~m}$ ) and the modern attack helicopter “Apache” (L: 17.57m, W: $16.43 \mathrm{~m}$, $\mathrm{H}: 4.9 \mathrm{~m})$ [6] are assumed as rectangular shape. The collection 
area and probability of striking per square kilometre per year are shown in table 1 . However, if the object is larger than the size above, it will have more probability of striking. In addition, in this calculation does not consider protrusion of the object such as poles and antenna.

The BS EN62305-4 [7] defines the of limits of negligibility of the number of direct striking on the structure $\left(N_{D}\right)$ and to the line $\left(N_{L}\right)$ as following

$\left(N_{D}+N_{L}\right)<0.01$

If the occurrence of dangerous events is more frequent than 1 every 100 years, it needs to be concern. Some of the calculated return period is significant so it needs lightning protection.

Table 1 Number of strike to typical objects where no other objects in vicinity to a structure will cause injury $\left(\mathrm{P}_{\mathrm{A}}\right)$ and the consequent loss to the damage $\left(L_{A}\right)$ [5]. The basic formula for $R_{A}$ can be expressed as

$R_{A}=N_{D} \times P_{A} \times L_{A}$

$\mathrm{L}_{\mathrm{A}}$ is determined by the proportion of number of people stay in a structure and proportion of occupied time. $\mathrm{L}_{\mathrm{A}}$ assumed as one in this paper because temporary structure is relatively small and focusing on single day rather than annual risk. The number of dangerous lightning flashes per $\mathrm{km}^{2}$ per year $\left(\mathrm{N}_{\mathrm{D}}\right)$ is multiplication of $\mathrm{N}_{\mathrm{g}}$ by $\mathrm{A}_{\mathrm{D}}$ as Equation 1 and $\mathrm{N}_{\mathrm{g}}$ can be expressed as

$N_{g}=0.1 \times T_{d}$

where, $T_{D}$ is the number of thunderstorm days for a location.

\begin{tabular}{|c|c|c|c|c|c|c|c|c|}
\hline \multirow[t]{2}{*}{ Object } & \multirow{2}{*}{$\frac{\mathbf{L}}{m}$} & \multirow{2}{*}{$\begin{array}{l}\mathbf{W} \\
m\end{array}$} & \multirow{2}{*}{$\begin{array}{l}\mathbf{H} \\
m\end{array}$} & \multicolumn{2}{|c|}{ collection area } & \multirow{2}{*}{\begin{tabular}{l}
\multicolumn{1}{c}{$\boldsymbol{N}_{\boldsymbol{D}}$} \\
$N_{g} 20$ \\
$\mathrm{~km}^{-2}$ year $^{-1}$
\end{tabular}} & \multirow{2}{*}{$\begin{array}{l}\text { number of } \\
\text { flash to } \\
\text { object }^{1)}\end{array}$} & \multirow{2}{*}{$\begin{array}{l}\text { return period } \\
\text { Year }^{-1}\end{array}$} \\
\hline & & & & $m^{2}$ & $\mathrm{~km}^{2}$ & & & \\
\hline Circus tent & 10 & 10 & 7 & 2325.442 & 0.002325 & 0.046509 & 0.0466 & 21.46 \\
\hline Camping tent & 6.1 & 3.8 & 2.15 & 281.588 & 0.000282 & 0.005632 & 0.0057 & 175.44 \\
\hline Metal shelter & 6.1 & 2.44 & 2.59 & 337.263 & 0.000337 & 0.006745 & 0.0068 & 147.06 \\
\hline $\begin{array}{l}\text { Tank } \\
\text { (Challenger 2) }\end{array}$ & 11.55 & 3.52 & 2.49 & 441.106 & 0.000441 & 0.008822 & 0.0089 & 112.36 \\
\hline $\begin{array}{l}\text { Helicopter } \\
\text { (Apache) }\end{array}$ & 17.57 & 14.63 & 4.9 & 1882.596 & 0.001883 & 0.037652 & 0.0377 & 26.53 \\
\hline
\end{tabular}

\section{POSSIBLE RISK}

The risk from a direct or indirect lightning strike is not different from the risk categorised in the BS EN 62305. If a temporary structure consist of fabric as in the case of a circus tent and marquee or if the structure contain explosives, such as gunpowder, gas and oil or if connected to electrical systems the risk shall increase significantly.

\section{A. Risk calculated according to BS EN62305-2}

Current standard BS EN62305 has recently updated for lightning protection to buildings and structures. While the standard applies to permanent buildings and structures in urban area, it includes a procedure for assessing lightning risk to any scenario. The standard defines methods to calculate the risks; R1 (risk of loss of human life), R2 (risk of loss of service to the public), R3 (risk of loss of cultural heritage) and $\mathrm{R} 4$ (risk of loss of economic value). R1 only be concerned in this paper. R2 and R3 are more close to permanent structure such as power plant (loss of service) and monument or castle (cultural heritage). R4 is less considerable than direct loss of life.

R1 has two components $\mathrm{R}_{\mathrm{A}}$ (lightning flash to the structure) and $R_{U}$ (lightning flash to an incoming service). Although $R_{U}$ may significant, this paper focuses on isolated temporary structure in open area. Risk depends on the number of dangerous events per annual $\left(\mathrm{N}_{\mathrm{D}}\right)$, the probability of damage
It can be analysed that a typical thunder day will have 0.1 lightning flashes in an area of $1 \mathrm{~km}^{2}$. Risk of one particular thunder day can be deduced from annual risk based on the standard from the approximation [8]. Assuming average $\mathrm{T}_{\mathrm{D}}$ for the UK is 7 , the number of lightning flashes per $\mathrm{km}^{2}$ on a thunder day is 0.1 , while the annual $\mathrm{N}_{\mathrm{g}}$ is 0.7 . The $\mathrm{A}_{\mathrm{D}}$ defined as "the intersection between the ground surface and a straight line with 1/3 slope which passes from the upper parts of the structure (touching it there) and rotating around it" [5]. The effect collection area is three times the height of the structure from the perimeter of the roofline as seen in Figure 2 . Assuming height of a person is $1.8 \mathrm{~m}$ in an open area, the $A_{D}$ will be similar to a circle with radius three times their height. So, $A_{D}$ is around $92 \mathrm{~m}^{2}$.

$A_{D}=(3 \times \text { height })^{2} \times \pi=(3 \times 1.8)^{2} \times \pi=91.61 m^{2}$

A strike within $3 \mathrm{~m}$ can cause serious side flash and step voltages [8], thus the $A_{D}$ for a person with neighbours within $3 \mathrm{~m}$ in open area event is about $222 \mathrm{~m}^{2}$.

$A_{D}=(3 \times \text { height }+3 m)^{2} \times \pi=(3 \times 1.8+3)^{2} \times \pi=221.67 m^{2}$

Applying Equation 2 for a rectangular isolated temporary circus tent in table 1 and event stage $(\mathrm{L}: 20 \mathrm{~m}, \mathrm{~W}$ : $20 \mathrm{~m}, \mathrm{H}$ : $15 \mathrm{~m})$, the $A_{D}$ is approximately $2,325 \mathrm{~m}^{2}$ and $10,360 \mathrm{~m}^{2}$, respectively. The likelihood the risk of lightning flash to an object during a local thunderstorm day for an isolated person in open area in the UK is approximately $0.7 \times 92 \times 10^{-6}=$ 
$6.44 \times 10^{-5}$ and that of person with crowd people in the area is approximately $0.7 \times 222 \times 10^{-6}=1.554 \times 10^{-4}$. That of an isolated structure for circus tent is approximately $0.7 \times 2325 \times$ $10^{-6} \approx 1.628 \times 10^{-3}$ and $0.7 \times 10360 \times 10^{-6} \approx 7.25 \times 10^{-3}$, respectively. Even though the value of $\mathrm{N}_{\mathrm{g}}$ for the UK is not high as regions in Central Africa, Indonesia, Northeast part of the USA and central South America, the estimated risk exceed tolerable risk. If a circus tent is stationed at a location for ten days and moved once in every ten days all over the world, there probability of risk would greater than the risk of the UK. This is because the $\mathrm{N}_{\mathrm{g}}$ over the UK is generally lower than the rest of the world. In terms of estimating $\mathrm{P}_{\mathrm{A}}$, the probability of injury due to a lightning flash, it is assumed as one for a person because a flash can cause injury to human in open area. For a temporary structure, this may vary. If a temporary structure has sufficient size of conductor with proper earth system, it can be regarded as a building with lightning protection. However, for a temporary structure there are many metallic materials such as poles, masts, metal roof of a container or stage and that can form a part of the lightning protection system. If it does not have sufficient earth, it can be considered as a building with a floating earth and shall have a greater risk of contact voltages than in a conventional building. Therefore, $\mathrm{P}_{\mathrm{A}}$ is assumed as one without protection measures and $10^{-2}$ with proper protection measures such as earth with electrical insulation of exposed parts or effective soil equipotentialisation [5]. The estimated likelihood risks for given condition are shown in Table 2.

Table 2 Estimated risk of an object in open area during a thunderstorm day

\begin{tabular}{|l|c|c|c|c|}
\hline \multicolumn{1}{|c|}{ Object } & $\begin{array}{c}\text { Ng } \\
\left(\boldsymbol{k m}^{-2} \text { year }^{-1}\right)\end{array}$ & $\begin{array}{c}\text { PA } \\
\text { (Without } \\
\text { LPS) }\end{array}$ & $\begin{array}{c}\text { AD } \\
\text { (m2) }\end{array}$ & $R A$ \\
\hline $\begin{array}{l}\text { Person } \\
\text { (Height: } \\
1.8 \mathrm{~m})\end{array}$ & 0.7 & 1 & 92 & $6.44 \times 10^{-5}$ \\
\hline $\begin{array}{l}\text { Crowd } \\
\text { (Height } \\
1.8 \mathrm{~m} \\
\text { spacing } \\
3 \mathrm{~m})\end{array}$ & 0.7 & 1 & 222 & $1.55 \times 10^{-4}$ \\
\hline $\begin{array}{l}\text { ircus tent } \\
\text { L: } 10 \mathrm{~m}, \\
\text { N: } 10 \mathrm{~m}, \\
\text { I: } 7 \mathrm{~m})\end{array}$ & 0.7 & 1 & 2,325 & $1.63 \times 10^{-3}$ \\
\hline $\begin{array}{l}\text { Event } \\
\text { stage } \\
\text { (L: } 20 \mathrm{~m}, \\
\begin{array}{l}\text { W: } 20 \mathrm{~m}, \\
\text { H: } 15 \mathrm{~m})\end{array}\end{array}$ & 0.7 & 1 & 10,360 & $7.25 \times 10^{-3}$ \\
\hline
\end{tabular}

\section{B. Tolerability of risk}

Tolerability of risk defined as maximum value of the risk which can be tolerated for the structure to be protected [5]. It means that the risk cannot be negligible or ignored and the risk need to be further reduced within the tolerable region by adopting measures to or below the tolerable limit. The maximum tolerable risk of loss of human life or permanent injury is defined as $1 \times 10^{-5}$ in the BS EN62305. However, the level of risk may inadequate for temporary structures because a single dangerous event can trigger more deaths. The estimated risks above are close to the tolerable risk of loss of human life and worst case is hundred times greater than the tolerable risk. Comparison of some levels of annual fatality in table 3 , the maximum annual risk of death for high risk groups is $1 \times 10^{-3}$, for public maximum risk of death is $1 \times 10^{-5}$ and natural back ground risk is $1 \times 10^{-7}$. The general people accept the risk of natural back ground, however, high risk work as $1 \times 10^{-3}$ and the risk of public accident $1 \times 10^{-4}$ are not acceptable risk of activities due to the risks is not tolerable at any conditions [8]. The risks of an isolated person, crowd people and a temporary structure in open area event during a thunderstorm are not smaller than tolerable value. Therefore, the estimated risks need to be reduced as low as broadly acceptable level in order to limit contact and step voltages by providing protection and warning notices.

Table 3 Levels of fatal risk [9]

\begin{tabular}{|l|l|l|}
\hline \multicolumn{1}{|c|}{$\begin{array}{c}\text { Per } \\
\text { annual }\end{array}$} & \multicolumn{1}{|c|}{ Risk } & \multicolumn{1}{c|}{ Risk of death } \\
\hline 1 in 100 & $1 \times 10^{-2}$ & $\begin{array}{l}\text { Five hours of solo rock climbing } \\
\text { every weekend }\end{array}$ \\
\hline 1 in 1000 & $1 \times 10^{-3}$ & $\begin{array}{l}\text { Work in high risk groups within } \\
\text { risky industries (e.g. mining) }\end{array}$ \\
\hline 1 in 10,000 & $1 \times 10^{-4}$ & $\begin{array}{l}\text { General risk of death in a traffic } \\
\text { accident }\end{array}$ \\
\hline 1 in 100,000 & $1 \times 10^{-5}$ & $\begin{array}{l}\text { Accident at work in the very safest } \\
\text { parts of industry }\end{array}$ \\
\hline 1 in & $1 \times, 000,000$ & Natural back ground by lightning \\
\hline
\end{tabular}

\section{Mitigation STRATEGY}

There is no perfect protection against lightning and no safe place in open area during thunderstorm due to the random and unpredictable behaviour of lightning flash. Even though the probability of being struck by lightning may be low, the consequences of fatality cannot be acceptable. Thus, any mitigation should be aimed to minimise human injuries and deaths against lightning related accidents for people who stay near or in an unprotected temporary structures during thunderstorms. In terms of temporary structures, they are used various purpose. Container box as transportable metal box may be used for as temporary office and accommodation in rural area construction site and deployed military, tent for wedding event, circus, storage or temporary housing for group such as military, stage for concert or event and marquee for festival. Their temporary length of service, installed location and availability of equipment are different, but, one common factor is that they are movable facility. Thus LPS for temporary structure need to be modular, light and durable with reasonable cost.

Air terminals can intercept the direct attachment of a lightning flash to a preferred point, convey the current to the earth and minimise the risks. Although providing an 
appropriate lightning protection for a temporary structure might be challenging, installing strike terminations such as air terminals, metal parts, overhead wire and lightning protection mast can reduce the risk. Air terminal provide zone of protection correspond with striking distance as seen in figure 3(a). Utilising an air terminal at the top of the structure can be done by attaching lightning rod at the end of poles with down conductor to the earth electrode for big tent as Figure 3(b) and marquee and installing lightning protection mast near the structure as 3(c). Lightning protection mast can be made foldable, constructible or telescopic and materials such as aluminium can be used to increase portability, allowing the mast to be moved to other locations.

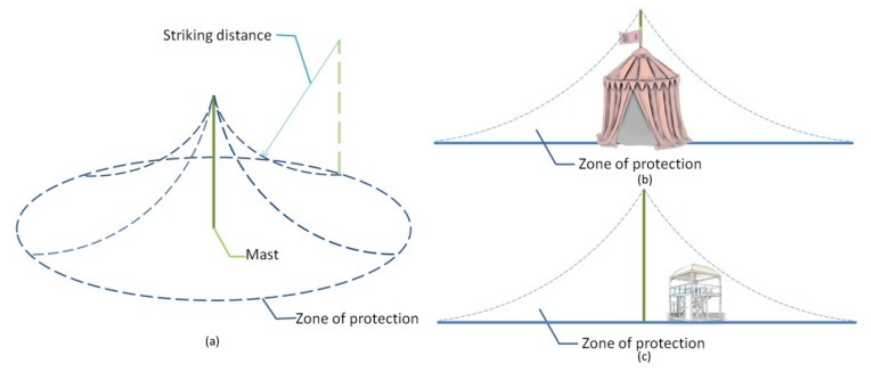

Figure 3 Zone of protection

\section{DISCUSSIONS AND CONCLUSIONS}

In this paper a practical analysis of providing protection for temporary structure in open area against lightning was proposed in order to tackle lightning hazards for people. As stated earlier the purpose of this paper was to provide a practical measure to reduce lightning hazard risks with minimum installation. The findings in this paper further stress the need for continued research on specific outdoor situations to arrive at more accurate and bespoke mitigation methods. It is necessary to research and develop concept of LPS to facilities of outdoor activity and open field. This study offer guidance on how practical lightning protection should be designed to prevent lightning hazard with minimum installation for temporary structure.

All measures should be aimed to minimise human injuries and deaths against lightning related accidents for people who stay or near a temporary structure in open area. The height of the mast can be significantly reduced by installing multiple masts. Reducing ground resistivity is also very significant measure to provide protection by reducing step voltage and side flash length. Increasing moisture content of the ground vicinity of the structure by adding water, chemical or natural material can reduce the ground resistivity and it will result in reducing the magnitude of step voltage and length of side flash. Providing multiple paths so as to split the lightning current by using poles inside of the structure as down conductor or install proper down conductor from the air terminal will also result in shorter side flash distance. Enclosing the poles or down conductor with electrically insulating material at least higher than height of people to minimise hazards from side flash and contact voltage. The combination of above measure will provide better protection with lower risk. It would not possible to cover all open area situation, however, it is hoped that this study will serve as a guidance to consider lightning protection in a practical way.

\section{REFERENCES}

[1] UN-Habitat, State of the world's cities 2010/2011-Bridging the urban divide, London: Earthscan, 2010.

[2] M. Ahrens, "Lightning fires and lightning strikes," National Fire Protection Association, Quincy, June 2013.

[3] BS EN 62305-1:2011 Protection against lightning Part 1: General principles, London: BSI, 2011.

[4] R. L. Holle, "Recent studies of lightning safety and demographics," in 22nd International Lightning Dectection Conference, Vienna, Austria, 2012.

[5] W. P. Roeder, "Backcountry lightning risk reduction-Lightning crouch versus standing with feet together," in 23rd International Lightning Detection Conference, Tucson, 2014.

[6] G. Dias, D. S. Gazzana, A. S. Bretas and M. Tello, "The need for standardization of human tolerability levels for lightning currents and voltages," in International Conference on Lightning Protection, Shanghai, 2014.

[7] BS EN 62305-2:2012 Protection against lightning Part 2: Risk management, London: BSI Standards Limited, 2013.

[8] C. B. Moore, W. Rison, J. Mathis and G. Aulich, "Lightning Rod Improvement Studies,” Journal of Applied Meteorology, vol. 39, pp. 593-609, May 2000.

[9] V. Cooray, "Attachment of lightning flashes to grounded structures," in Lightning protection, London, The institution of Engineering and Technology, 2010, pp. 165-176. 